\title{
APLIKASI LOUVER UNTUK PENGONTROLAN PENCAHAYAAN ALAMI PADA RUMAH TINGGAL
}

\author{
Yunita Ardianti Sabtalistia \\ Dosen Prodi S1 Arsitektur, Fak.Teknik, Universitas Tarumanagara, Jakarta \\ e-mail: yunitas@ft.untar.ac.id \\ Sintia Dewi Wulanningrum \\ Dosen Prodi S1 Arsitektur, Fak.Teknik, Universitas Tarumanagara, Jakarta \\ e-mail: sintiaw@ft.untar.ac.id
}

\begin{abstract}
ABSTRAK
Pemanfaatan pencahayaan alami pada rumah tinggal dapat tercapai secara optimal jika mampu memanfaatkan bukaan-bukaan, seperti: jendela, skylight, dan ventilasi. Pencahayaan matahari yang masuk melewati jendela dapat diatur kuantitasnya dengan menggunakan louver. Pada masa pandemi Corona seperti saat ini menyebabkan waktu kita sebagian besar dihabiskan di rumah. Berdasarkan permasalahan tersebut maka penelitian ini bertujuan mengoptimalkan penggunaan louver pada rumah tinggal khususnya pada ruang kerja, dapur, dan ruang makan agar memberikan pencahayaan alami yang memenuhi standard minimal yang sudah ditentukan oleh SNI 6197:2020. Sampel penelitian yang digunakan adalah rumah tipe 27/60 yang menghadap ke arah barat daya. Metode yang digunakan adalah metode eksperimen dengan menggunakan simulasi Ecotect. Ada 3 model rumah yang disimulasikan, yaitu: model rumah eksisting dan 2 model rumah yang dimodifikasi baik dari bentuk rumah dan model bukaannya. Ketiga model rumah tersebut disimulasikan menjadi 3 kondisi, yaitu: tanpa louver, horizontal louver, dan vertical louver. Hasil penelitian menunjukkan bahwa penggunaan horizontal louver lebih mampu mengurangi cahaya matahari yang masuk dibandingkan vertical louver. Model yang terbaik adalah model 2 dengan solar control berupa horizontal louver. Hal tersebut disebabkan karena model 2-horizontal louver mempunyai selisih nilai lux dengan SNI yang paling rendah dan mempunyai tingkat uniformity ratio cukup tinggi.
\end{abstract}

\section{Kata kunci : Daylighting Level, Louver, Pencahayaan Alami, Rumah Tinggal, Uniformity Ratio}

\begin{abstract}
The amount of sunlight that enters through the window can be adjusted using a louver. During the current Corona pandemic, most of our time is spent at home. Based on these problems, this study aims to optimize the use
\end{abstract}


of louvers in residential homes, especially in the workspace, kitchen, and dining room in order to provide natural lighting that meets the minimum standards that have been determined by SNI 6197:2020. The research sample used is a house type 27/60 facing southwest. The method used is an experimental method using Ecotect simulation. There are 3 simulated house models, namely: the existing house model and 2 modified house models both from the shape of the house and the opening model. The three house models were simulated into 3 conditions, namely: without louver, horizontal louver, and vertical louver. The results showed that the use of a horizontal louver is better able to reduce incoming sunlight than a vertical louver. The best model is model 2 with solar control in the form of a horizontal louver. This is because the model has the lowest lux value difference with SNI and has a fairly high level of uniformity ratio.

\section{Keywords : Daylighting Level, House, Louver, Natural Lighting, Uniformity Ratio}

\section{PENDAHULUAN}

Salah satu cara mengurangi penggunaan listrik adalah dengan mengurangi penggunaan lampu. Oleh karena itu pencahayaan alami melalui bukaan, seperti: jendela, ventilasi, dan skylight yang ada di dalam rumah perlu dioptimalkan agar penggunaan lampu dapat dihindari dari pagi sampai sore hari. Louver (kisi-kisi) merupakan salah satu alat pengontrol cahaya matahari yang masuk melalui jendela.

Berdasarkan standard SNI 6197:2020 kebutuhan pencahayaan minimal untuk ruang kerja adalah 350 lux, dapur minimal sebesar 250 lux, dan ruang makan minimal sebesar 100 lux. Jika cahaya matahari yang masuk ke dalam ruangan-ruangan tersebut melebihi standard minimal yang sudah ditentukan maka penggunaan lampu tidak lagi diperlukan untuk kegiatan di dalam rumah.

Kisi-kisi (louver) berfungsi untuk mengurangi intensitas cahaya matahari yang masuk ke dalam ruangan. Louver bisa diatur jarak antar louver, sudut kemiringan, dan lebar louver. Dengan mengatur jarak antar louver dapat mengontrol intensitas cahaya matahari yang masuk. Salah satu penggunaan louver yang kurang tepat adalah louver di Sekolah Dasar Islam Terpadu (SDIT) Al Uswah di Surabaya. Penggunaan louver dengan jarak antar louver yang terlalu rapat di koridor ruangan kelas menyebabkan cahaya matahari yang masuk ke dalam ruangan kelas menjadi terlalu sedikit sehingga ruangan kelas menjadi terlalu gelap (Ekasiwi, S.N dkk, 2020:70). Oleh karena itu perlu memperlebar jarak antar louver dan sudut kemiringan diatur menjadi 0 derajat (terbuka penuh) agar cahaya matahari lebih banyak masuk ke dalam ruangan kelas. 
Louver bisa dipasang dengan arah horisontal dan vertikal. Perbedaan arah pemasangan louver tersebut dapat memberikan pengaruh terhadap besar kecilnya daylihgting level yang masuk ke dalam rumah. Penelitian ini bertujuan untuk mengoptimalkan penggunaan louver pada rumah tinggal khususnya pada ruang kerja, dapur, dan ruang makan agar memberikan pencahayaan alami yang memenuhi standard minimal yang sudah ditentukan oleh SNI 6197:2020. Pada penelitian ini, louver dipasang di sisi dalam jendela dengan tujuan untuk mempermudah pemeliharaan.

\section{TINJAUAN PUSTAKA}

Semakin tinggi daylighting level dalam suatu ruangan maka membuat ruangan menjadi semakin terang. Semakin tinggi tingkat keseragaman cahaya maka semakin baik pula kualitas pencahayaan alami karena selisih tingkat pencahayaan yang diukur dengan satuan lux tidak terlalu jauh antara nilai minimal dengan nilai rata-ratanya (Sabtalistia, 2017: 199). Adapun rumus perhitungan uniformity ratio adalah sebagai berikut (Freewan dkk, 2009):

$$
\text { Uniformity Ratio }=\frac{\text { minimal Illuminance }}{\text { average Illuminance }} \times 100
$$

$$
\begin{aligned}
& \text { Keterangan : Uniformity Ratio = Tingkat Keseragaman Cahaya (\%) } \\
& \text { Minimal Illuminacne = Level Pencahayaan Minimal (Lux) } \\
& \text { Average Illuminance }=\text { Level Pencahayaan Rata-rata } \\
& \text { (Lux) }
\end{aligned}
$$

Penelitian tentang pengujian uniformity ratio pada shading device ruangan kelas di SMAK Penabur Summarecon, Bekasi pernah dilakukan pada tahun 2017 (Sabtalistia, 2017:200). Ruangan kelas yang diuji adalah ruangan kelas berukuran $8,15 \times 9,05$ meter yang mempunyai orientasi jendela menghadap utara dan selatan (Sabtalistia, 2017:197). Shading device yang diuji coba adalah eggcrate dengan panjang $1,12 \mathrm{~m}$ dan tinggi $3,79 \mathrm{~m}$ (kondisi eksisting), horizontal overhang dengan panjang $1,20 \mathrm{~m}$, horizontal louver dengan lebar $0,3 \mathrm{~m}$, vertical louver dengan lebar $0,3 \mathrm{~m}$ dan tinggi $1,10 \mathrm{~m}$, dan light shelf dengan panjang 1,65 $\mathrm{m}$ (Sabatalistia, 2017:199). Horizontal louver dan vertical louver dipasang di luar jendela. Pemasangan louver yang dipasang di sisi luar jendela tersebut bertujuan untuk mengurangi panas matahari yang masuk ke dalam bangunan. Hasil peneltian tersebut menunjukkan bahwa model eggcrate memperoleh uniformity ratio tertinggi (89\%) dan model vertical louver memperoleh uniformity ratio terendah (62\%). Horizontal louver memperoleh uniformity ratio yang lebih besar daripada vertical louver, yaitu sebesar $82 \%$. 


\section{METODE PENELITIAN}

Penelitian ini bertujuan menemukan model louver yang memberikan pencahayaan alami pada rumah tinggal. Louver berfungsi sebagai pengatur intensitas pencahayaan alami yang masuk ke dalam bangunan. Ada 2 jenis louver jika ditinjau dari arah pemasangan, yaitu: louver yang dipasang horisontal (horizontal louver) dan louver yang dipasang vertikal (vertical louver). Sudut kemiringan louver juga dapat diatur sesuai kebutuhan. Penelitian ini merupakan penelitian lanjutan dari penelitian periode sebelumnya (Sabtalistia dkk, 2021:63). Penelitian sebelumnya telah menghasilkan model bukaan (ditinjau dari luas jendela dan luas skylight) yang paling mampu memberikan daylighting level paling optimal. Pada penelitian ini akan diuji coba model louver yang paling mampu mengontrol cahaya sehingga dapat mengoptimalkan pencahayaan alami pada rumah tinggal.

Metode yang digunakan adalah metode eksperimen. Alat simulasi yang digunakan adalah Ecotect. Parameter penelitian yang digunakan adalah Daylighting Level yang mempunyai satuan lux dan Uniformity Ratio yang mempunyai satuan persen. Daylighting level menjadi optimal jika nilainya melebihi standard SNI 6197:2020 dan tidak terlalu jauh nilainya dengan nilai minimal SNI tersebut. Uniformity ratio semakin tinggi nilainya maka akan semakin baik karena cahaya yang ada di dalam ruangan semakin seragam. Metode eksperimen lebih berfokus pada hubungan sebab dan akibat (Groat dkk, 2002). Model louver menjadi penyebab sedangkan Daylighting Level dan Uniformity Ratio menjadi akibat.

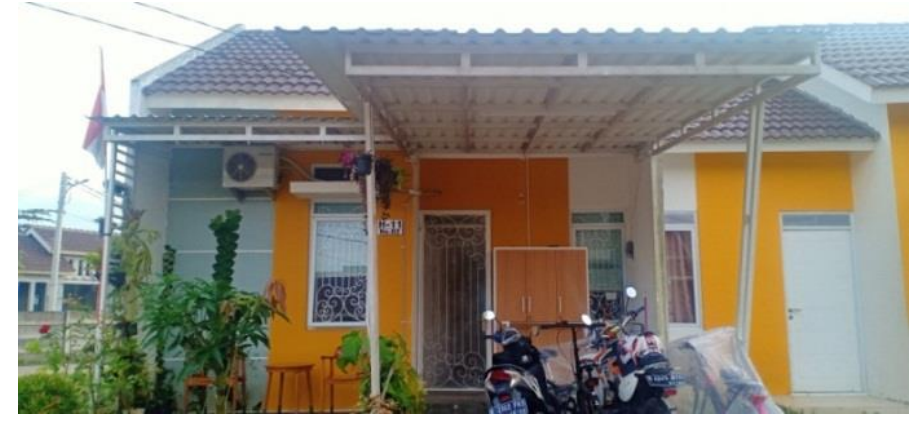

Gambar. 1

Tampak Depan Sampel Penelitian

Sumber: Sabtalistia dkk, 2021:67

Sampel penelitian yang digunakan masih sama dengan penelitian sebelumnya, yaitu rumah tinggal yang berada di Perumahan Forest Hill, Cluster the Village, Blok H11, No.2, Parung Panjang, Bogor, Jawa Barat (Gambar 1). Rumah tersebut mempunyai tipe 27/60, menghadap ke arah barat daya, dan berada di posisi hook sehingga tampak samping kiri rumah tidak ada bukaan sama sekali (Gambar 2 kiri). Tampak belakang terdapat 1 
buah jendela dan skylight yang di bawahnya terdapat taman dan area jemur (Gambar 2 kanan).
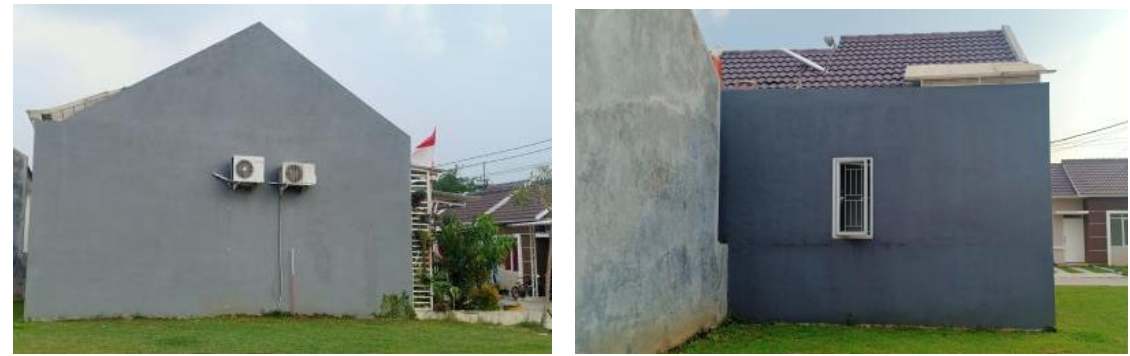

Gambar. 2

Tampak Samping Kiri dan Tampak Belakang Sampel Penelitian

Sumber: Sabtalistia dkk, 2021: 67

Pengukuran daylighting level menggunakan alat ukur yang disebut luxmeter (Gambar 3). Pengukuran dilakukan pada hari Kamis, 17 Desember 2020 pukul 12.00 WIB. Pengukuran dilakukan pada saat kondisi langit cerah (tidak berawan). Pada saat pengukuran pintu depan ditutup, semua jendela tidak ditutup korden, dan tidak ada jemuran di area jemur. Hasil pengukuran menunjukkan ruang kerja mempunyai nilai lux sebesar 364 lux, ruang makan sebesar 1082 lux, dan dapur 568 lux (Gambar 4).

Tahap selanjutnya setelah melakukan pengukuran dengan luxmeter adalah mensimulasikan sampel penelitian dengan Ecotect pada tgl 17 Desember pukul 12.00. Gambar 5 menunjukkan daylighting level hasil perhitungan dengan Ecotect yang mempunyai posisi titik ukur sama dengan titik ukur luxmeter. Hasilnya menunjukkan ruang kerja mempunyai nilai lux sebesar 356 lux, dapur sebesar 546 lux, dan ruang makan sebesar 1116 lux. Tiga nilai tersebut tidak terlalu jauh berbeda nilainya dengan hasil luxmeter. Dengan nilai lux yang tidak terlalu berbeda antara hasil luxmeter dan Ecotect maka selanjutnya bisa dilakukan eksperimen menggunakan Ecotect karena hasil Ecotect mendekati kondisi aslinya.

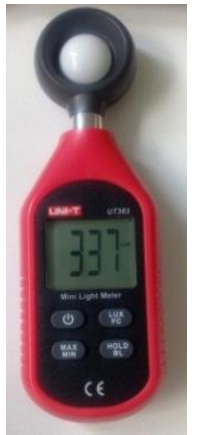

Gambar.3

Luxmeter

Sumber: Dokumentasi, Desember 2020

PAWON: Jurnal Arsitektur, Nomor 02 Volume 5, Juli-Desember Tahun 2021, ISSN 2597-7636 


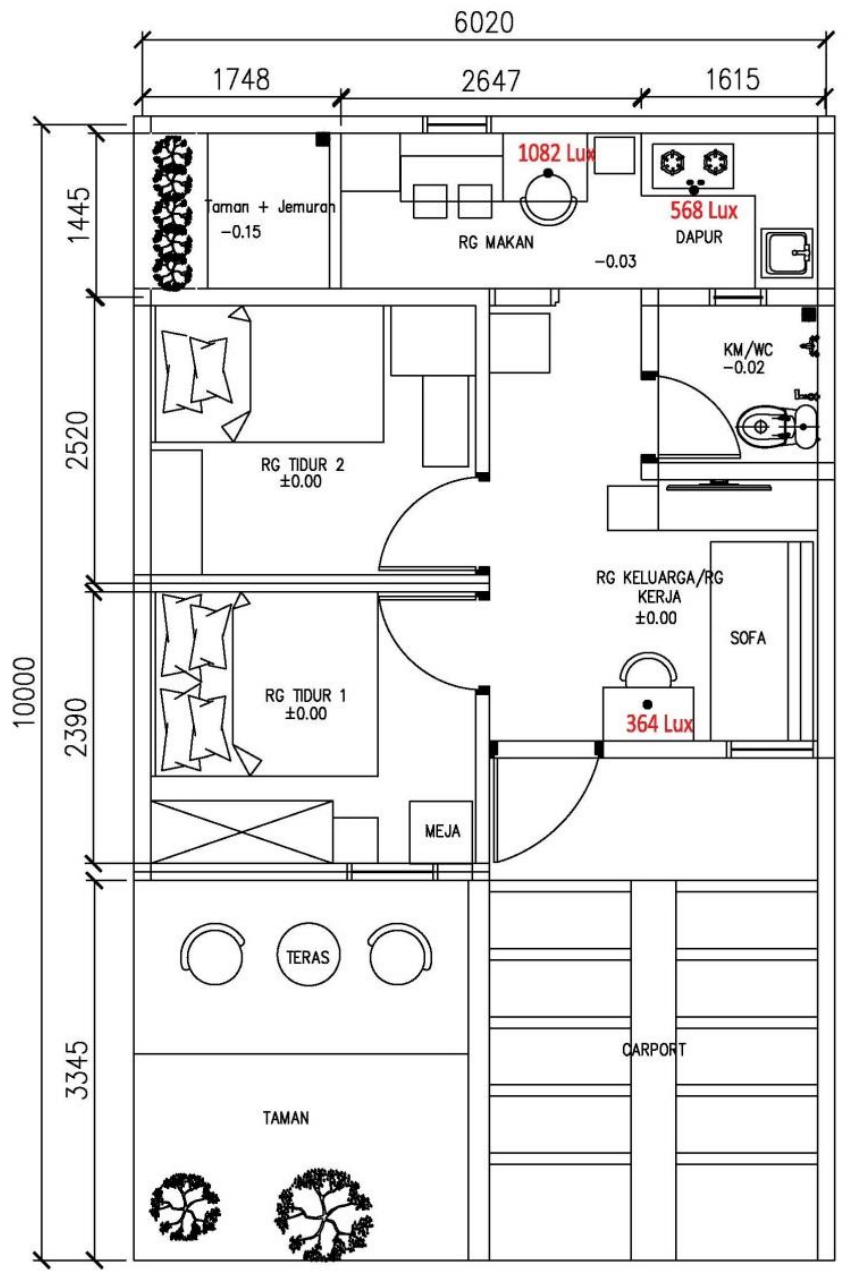

Gambar. 4

Denah Sampel Penelitian (Scale to Fit) dan Hasil Ukur dengan Luxmeter Sumber: Survei, Desember 2020

Model rumah yang dieksperimen ada 3 model, yaitu: model eksisting, model 1, dan model 2 (Gambar 6). Model eksisting adalah model rumah asli sesuai kondisi eksisting tapi tanpa atap kanopi U-PVC di carport dan teras. Model 1 dan model 2 adalah model eksisting yang divariasikan model bukaannya tapi tetap mempunyai denah yang sama dengan kondisi eksisting. Horizontal louver dan vertical louver dicoba untuk disimulasikan ke dalam 3 model tersebut (Gambar 7). Lebar louver dan jarak antar louver diatur sebesar $5 \mathrm{~cm}$. Sudut kemiringan louver diatur sebesar 0。 (louver dalam keadaan terbuka penuh). 


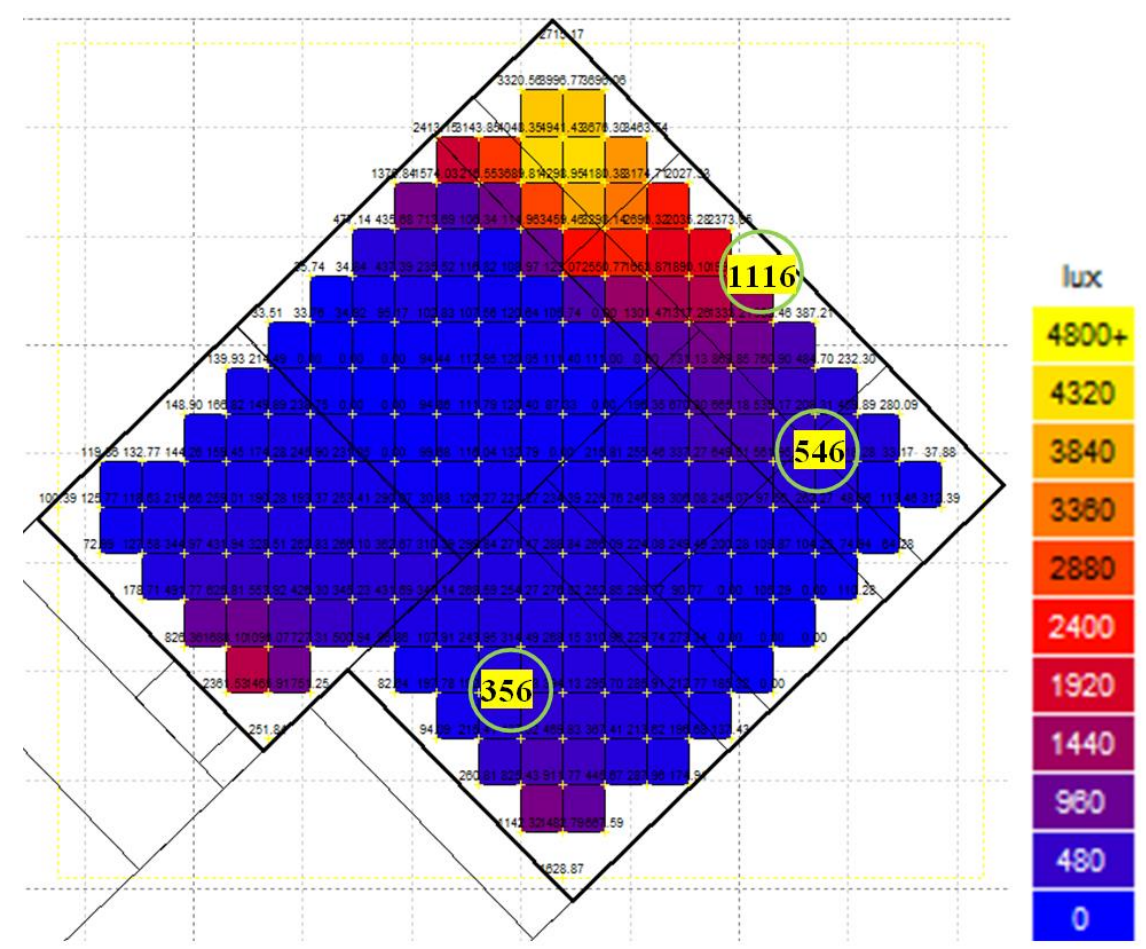

Gambar. 5

Simulasi Daylighting Level dengan Ecotect pada Sampel Penelitian Sumber: Ecotect, Desember 2020
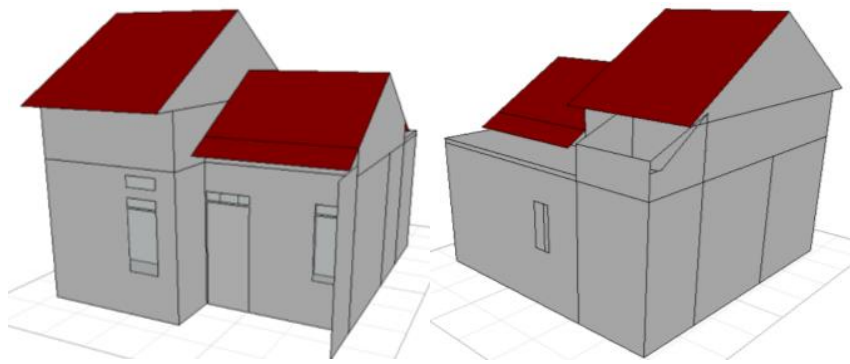

(a)
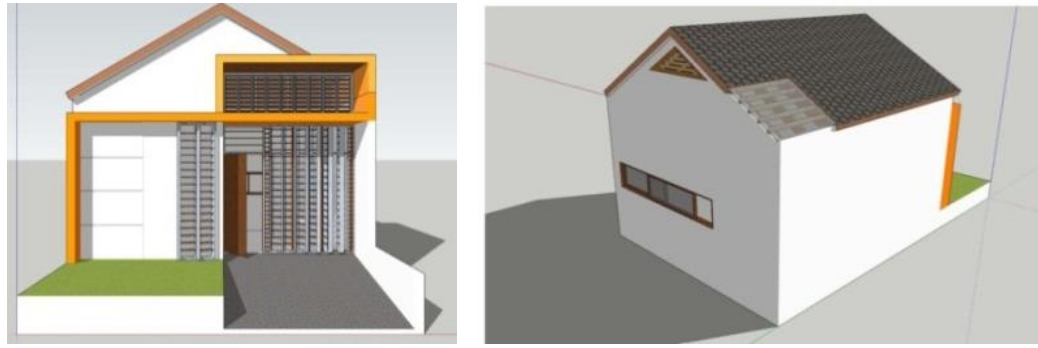

(b)

PAWON: Jurnal Arsitektur, Nomor 02 Volume 5, Juli-Desember Tahun 2021, ISSN 2597-7636 

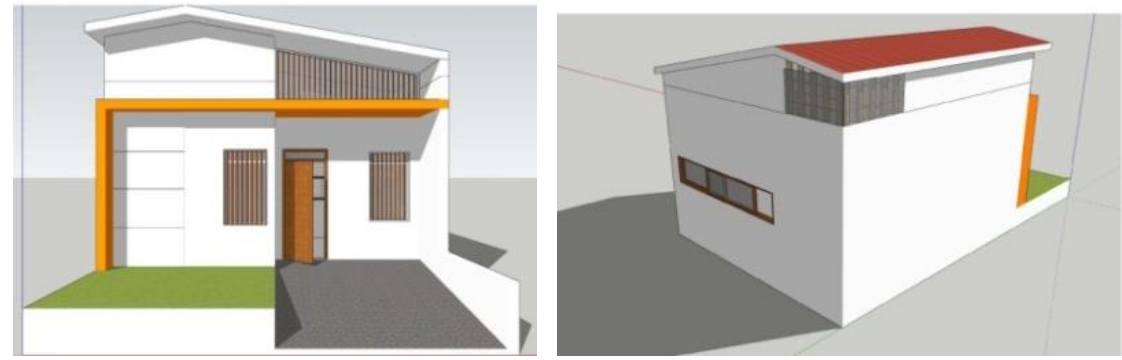

(c)

Gambar. 6

Model Rumah yang Dieksperimen: (a) Model Eksisting; (b) Model 1; (c) Model 2 Sumber: Penulis, Juni 2021

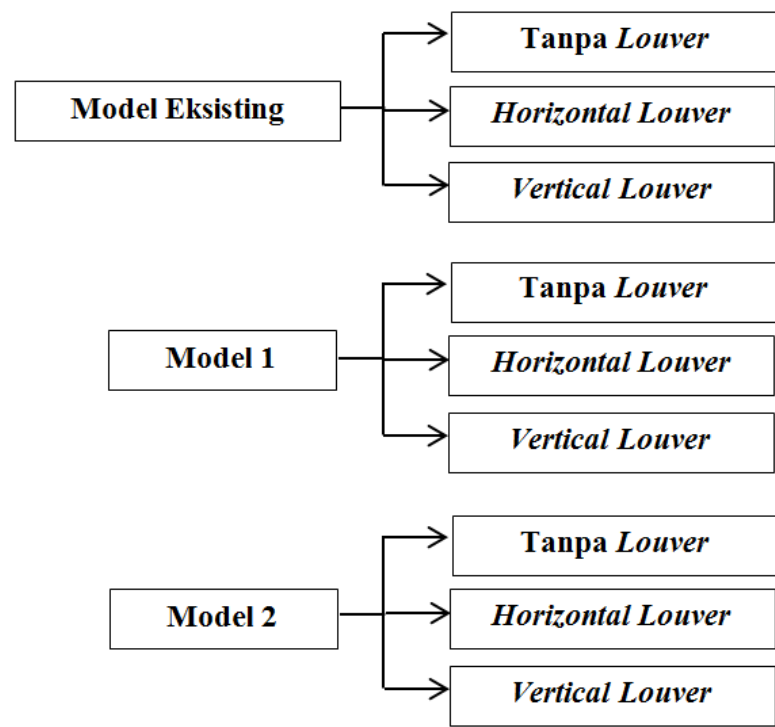

Gambar. 7

Model Eksperimen yang Disimulasikan dengan Ecotect

Sumber: Analisa Penulis, Juni 2021

\section{HASIL DAN PEMBAHASAN}

\subsection{Pengaruh Louver terhadap Ketiga Model Rumah}

Dari ketiga model rumah dapat dibuktikan bahwa penggunaan horizontal louver paling mampu mengurangi nilai Lux sehingga mendekati SNI (Gambar 8). Jika tidak menggunakan louver sama sekali membuat ruangan-ruangan pada ketiga model rumah menjadi terlalu terang terutama pada ruang kerja dan ruang makan (Gambar 9).

PAWON: Jurnal Arsitektur, Nomor 02 Volume 5, Juli-Desember Tahun 2021, ISSN 2597-7636 


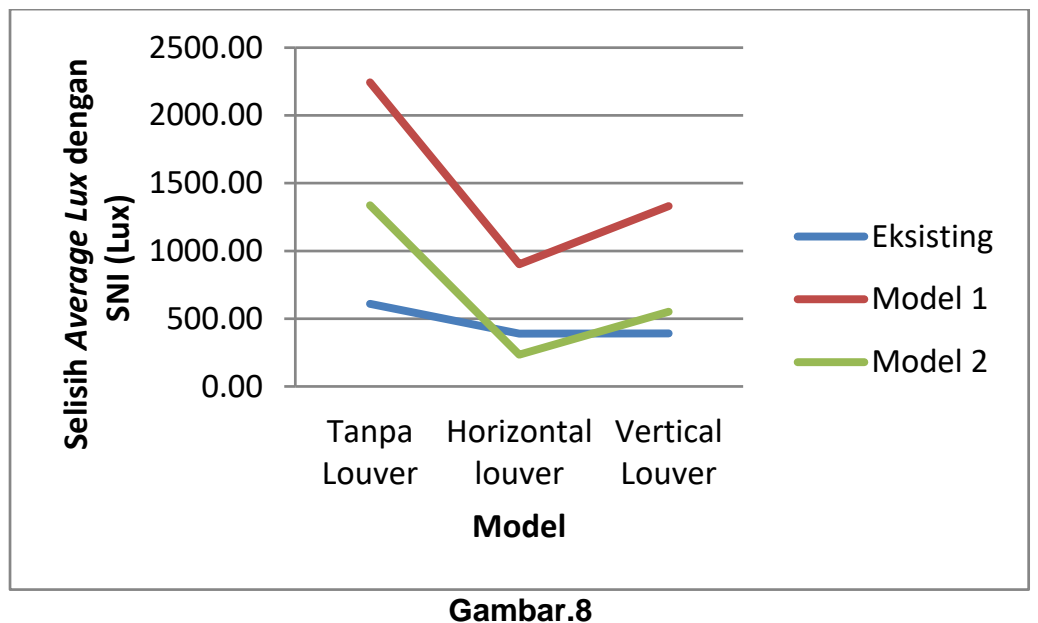

Perbandingan Selisih Lux Rata-rata dengan SNI 6197:2020 pada Ketiga Model Rumah Sumber: Ecotect, Juni 2021

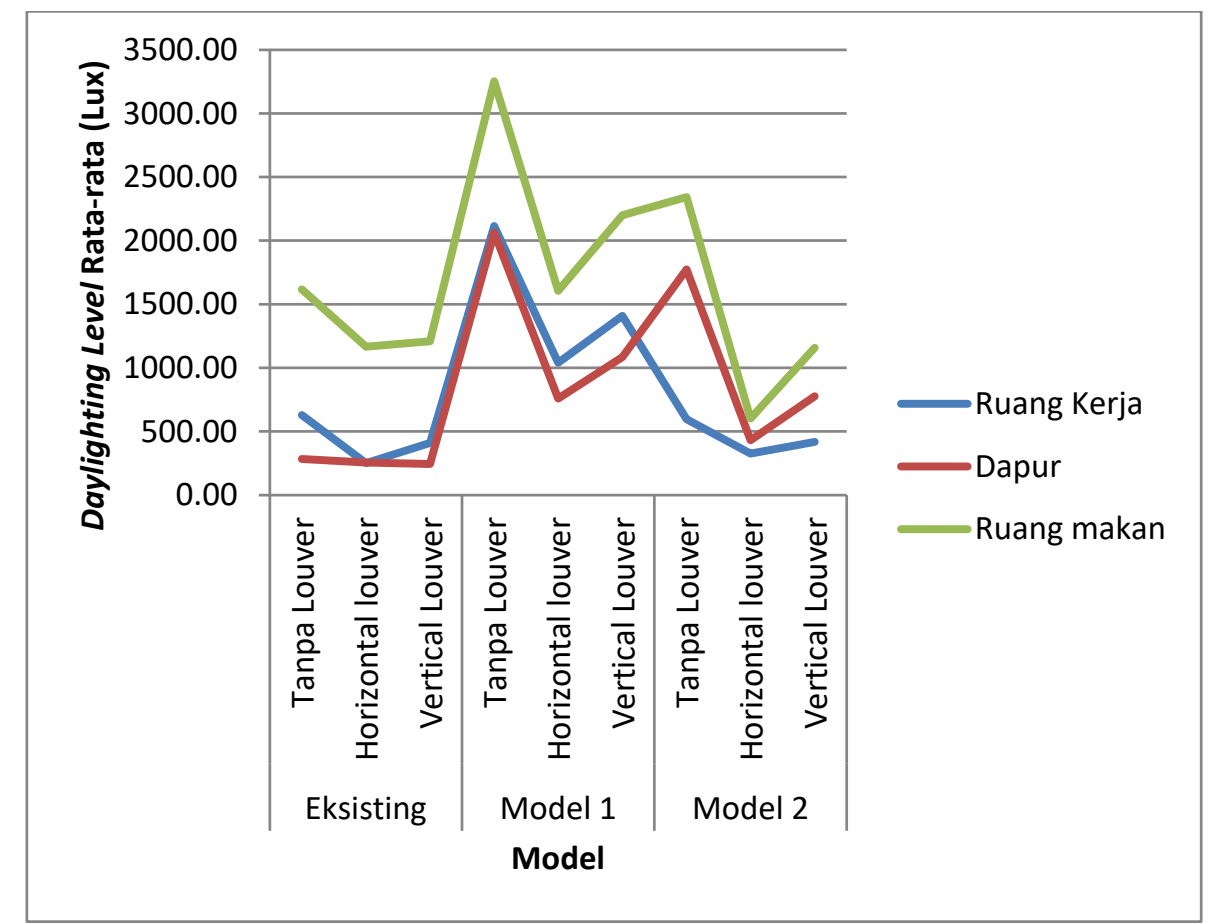

\section{Gambar.9}

Perbandingan Daylighting Level Rata-rata di Ruang Kerja, Dapur, dan Ruang Makan pada Ketiga Model Rumah

Sumber: Ecotect, Juni 2021

Dari ketiga model, ruangan-ruangan yang mempunyai nilai Lux lebih kecil daripada 500 Lux adalah model eksisting dan model 2 (Gambar 9). Model 1 mempunyai ruangan-ruangan yang terlalu terang karena nilai Lux 
nya jauh melebihi 500 Lux. Model eksisting mempunyai nilai Lux yang hampir mendekati SNI untuk dapur. Namun, uniformity ratio untuk model eksisting cukup rendah, hanya berkisar antara 24,04-30,23\% (Gambar 10). Yang mempunyai uniformity ratio tertinggi adalah model 1 tetapi perbedaan nilai lux terlalu tinggi jika dibandingkan SNI (ruangan terlalu terang).

Model 2 dengan penggunaan horizontal louver mempunyai selisih Lux dengan SNI paling rendah dan mempunyai tingkat uniformity ratio cukup tinggi (Gambar 8 dan 10). Oleh karena itu dapat disimpulkan bahwa model rumah yang terbaik jika ditinjau dari optimalisasi pencahayaan alaminya adalah model 2 dengan horizontal louver.

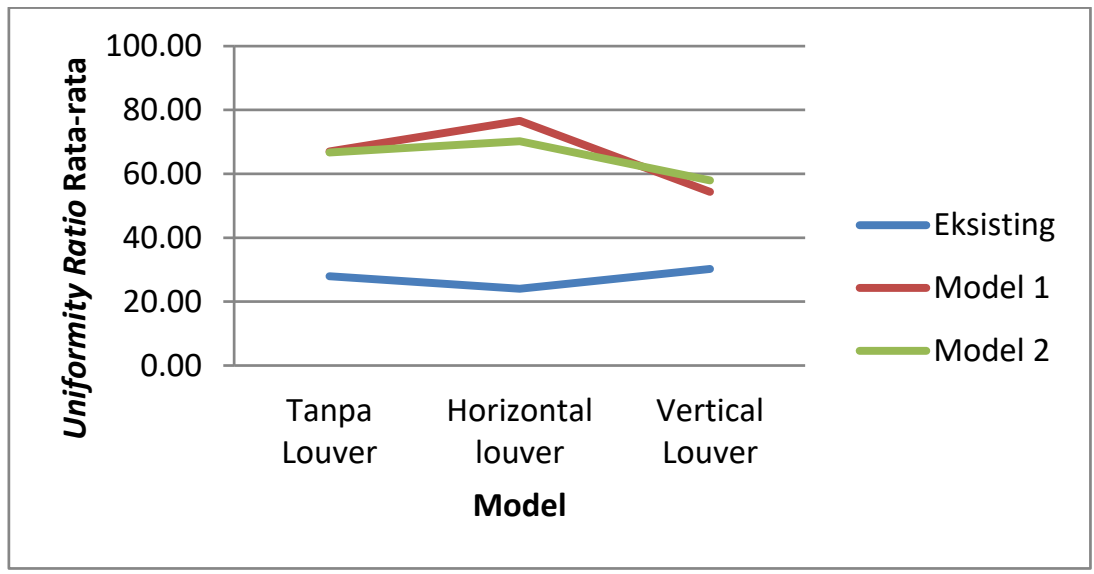

Gambar.10

Perbandingan Uniformity Ratio Rata-rata pada Ketiga Model Rumah Sumber: Ecotect, Juni 2021

\subsection{Distribusi Cahaya pada Model Terbaik (Model 2-Horizontal Louver)}

Daylighting level pada ruang kerja cenderung lebih tinggi pada area yang berdekatan dengan jendela dan area yang berhubungan dengan area belakang (ruang makan) (Gambar 11). Pada area yang jauh dari jendela cenderung mempunyai nilai lux yang lebih rendah tetapi masih cukup terang. Posisi meja kerja berada di dekat jendela. Daylighting level pada meja kerja cukup tinggi, yaitu berkisar antara 210,55 sampai dari 552,42 Lux.

Meja dapur berbentuk siku (L) (Gambar 12). Nilai lux pada bidang meja dapur yang digunakan untuk tempat memasak cukup tinggi (melebihi SNI minimal untuk dapur), yaitu berkisar antara 351,81 sampai 508,18 Lux.

Pada area ruang makan, masuknya cahaya matahari tidak hanya berasal dari jendela yang ada depan meja makan tetapi juga dari skylight yang ada di ruang jemuran (Gambar 13). Oleh karena itu distribusi cahaya yang ada di ruang makan cenderung merata. Nilai lux pada meja makan 
cenderung cukup tinggi karena melebihi 100 Lux (nilai minimal SNI). Adapun nilai lux yang ada di meja makan berkisar 144,74 Lux sampai 798,11 Lux

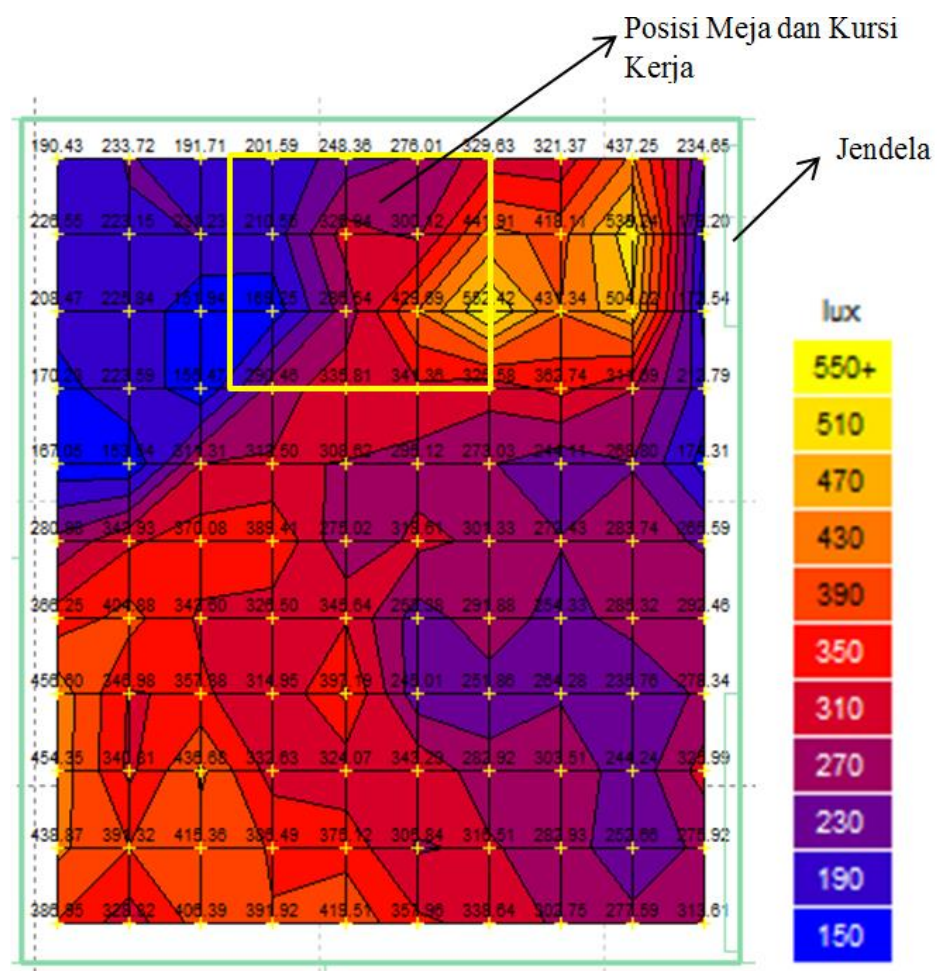

Gambar.11
Daylighting Level di Ruang Kerja pada Model 2-Horizontal Louver

Sumber: Ecotect, Juni 2021

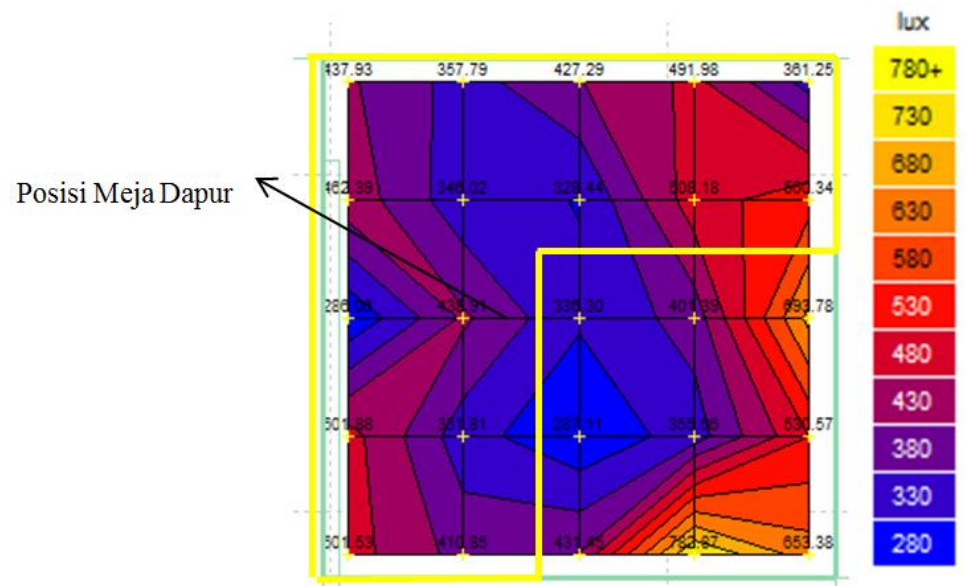

Gambar.12

Daylighting Level di Dapur pada Model 2-Horizontal Louver Sumber: Ecotect, Juni 2021

PAWON: Jurnal Arsitektur, Nomor 02 Volume 5, Juli-Desember Tahun 2021, ISSN 2597-7636 


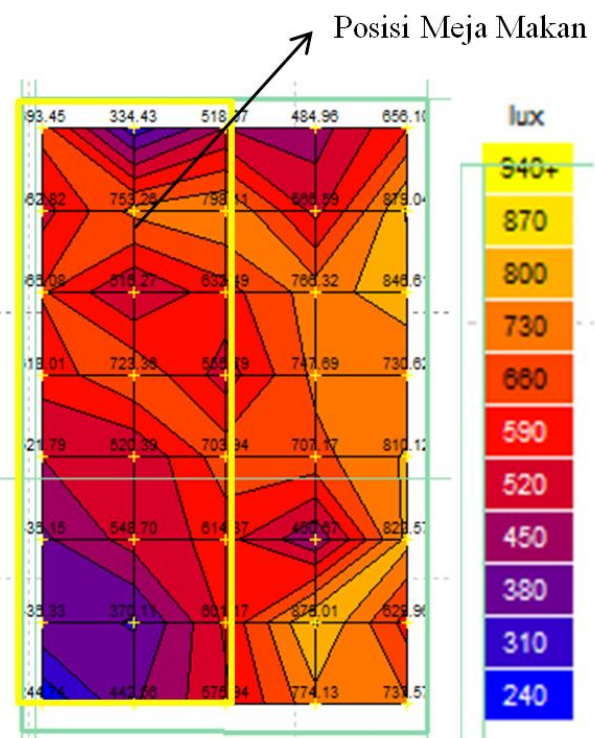

Gambar.13

Daylighting Level di Ruang Makan pada Model 2-Horizontal Louver Sumber: Ecotect, Juni 2021

\subsection{Perbandingan Pengaruh Penggunaan Horizontal Louver dan Vertical Louver terhadap Daylighting Level}

Pola distribusi cahaya keseluruhan ruangan pada horizontal louver cenderung lebih merata daripada vertical louver (Gambar 14 dan 15). Daylighting level rata-rata pada horizontal louver adalah 326,20 Lux sedangkan pada vertical louver sebesar 468,29 Lux. Nilai daylighting level horizontal louver cenderung lebih rendah daripada vertical louver.

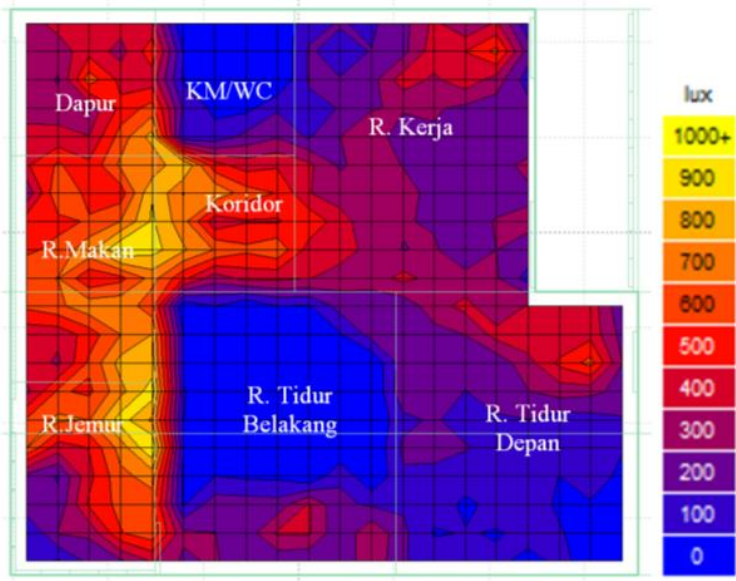

Gambar.14

Daylighting Level Keseluruhan Ruang pada Model 2-Horizontal Louver

Sumber: Ecotect, Juni 2021

PAWON: Jurnal Arsitektur, Nomor 02 Volume 5, Juli-Desember Tahun 2021, ISSN 2597-7636 


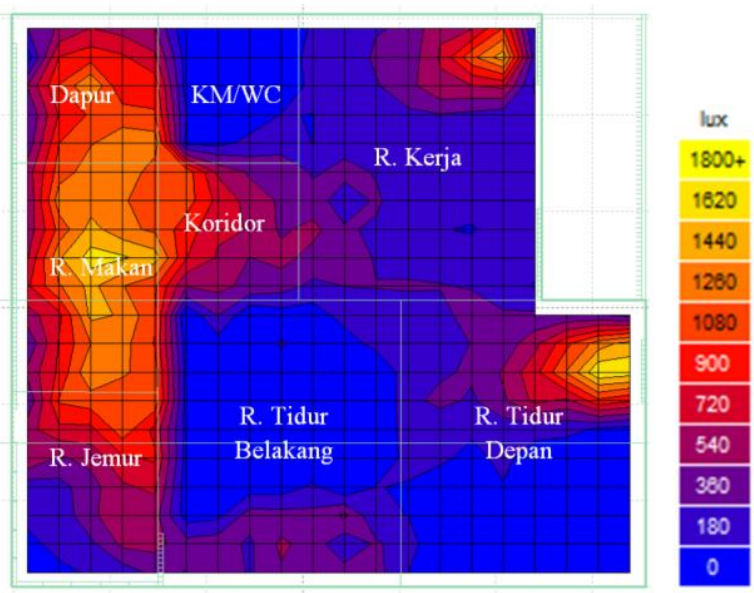

Gambar. 15

Daylighting Level Keseluruhan Ruang pada Model 2-Vertical Louver Sumber: Ecotect, Juni 2021

Dengan menggunakan vertical louver, area yang berdekatan dengan jendela ruang tidur depan dan ruang kerja cenderung lebih terang daripada jika menggunakan horizontal louver (Gambar 14 dan 15). Hal tersebut membuktikan bahwa penggunaan horizontal louver lebih mampu mengurangi cahaya yang masuk daripada vertical louver.

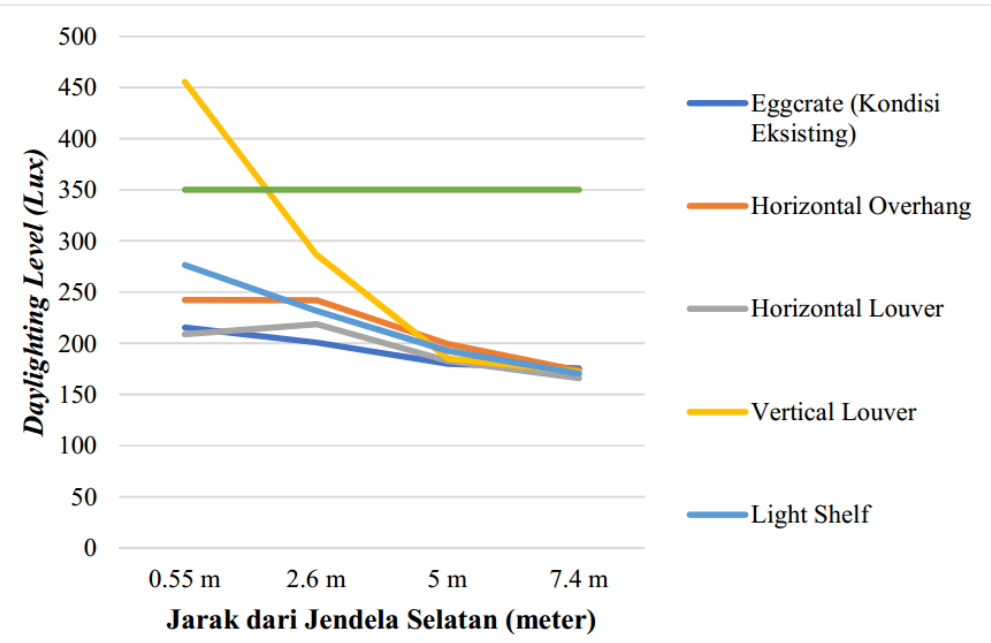
Gambar. 16
Pengaruh Perubahan Jarak terhadap Daylighting Level pada Berbagai Shading Device Sumber: Sabtalistia, 2017:200

Pada penelitian sebelumnya (Sabtalistia, 2017:200) juga membuktikan bahwa daylighting level pada horizontal louver mempunyai

PAWON: Jurnal Arsitektur, Nomor 02 Volume 5, Juli-Desember Tahun 2021, ISSN 2597-7636 
nilai lebih rendah daripada vertical louver terutama pada area yang berada di dekat jendela (0,55 meter) (Gambar 16). Gambar 17 menunjukkan perbandingan daylighting level pada Eggcrate dengan vertical louver. Penggunaan vertical louver menyebabkan area yang berada di dekat jendela menjadi terlalu terang sehingga menurunkan tingkat keseragaman cahaya (uniformity ratio).

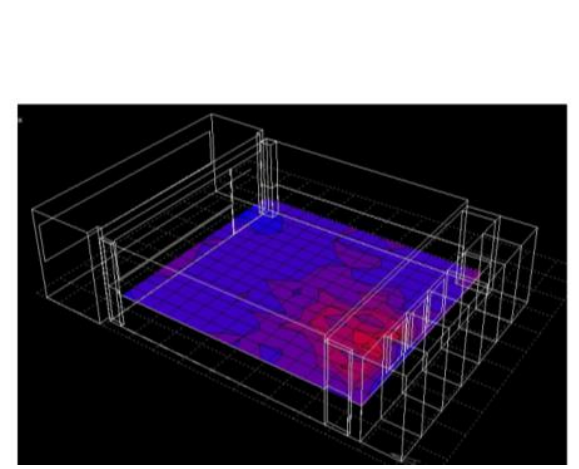

(a)

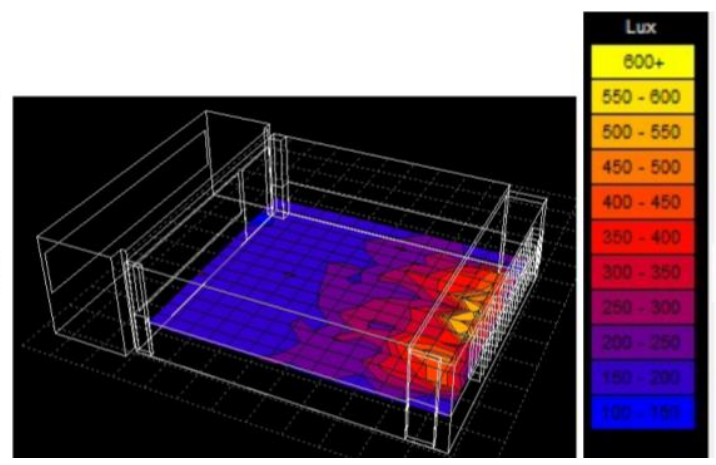

Gambar. 17

Perbandingan Daylighting Level pada: (a) Eggcrate dan (b) Vertical Louver Sumber: Sabtalistia, 2017:201

Pada penelitian di bulan Juni 2021 (Gambar 14 dan 15), louver diletakkan di dalam jendela untuk memudahkan perawatan sedangkan pada penelitian Sabtalistia, 2017 (Gambar 16 dan 17), louver diletakkan di luar jendela untuk mengurangi panas yang masuk ke dalam bangunan. Meskipun terjadi perbedaan perletakan louver, ternyata hasilnya menunjukkan kesamaan, yaitu penggunaan horizontal louver lebih mampu mengurangi cahaya yang masuk daripada vertical louver.

\section{KESIMPULAN DAN SARAN}

Dari ketiga model rumah yang diuji coba dengan Ecotect dapat dibuktikan bahwa model 2 dengan penggunaan horizontal louver adalah model yang terbaik jika dilihat dari optimalisasi pencahayaan alaminya. Model 2 mempunyai selisih Lux dengan SNI paling rendah dan mempunyai tingkat uniformity ratio cukup tinggi. Penggunaan horizontal louver lebih mampu mengurangi cahaya yang masuk jika dibandingkan vertical louver. Hal tersebut dibuktikan dengan nilai lux keseluruhan ruang yang cenderung lebih rendah jika menggunakan horizontal louver.

Lebar louver dan jenis material louver yang ada di pasaran sangat beraneka ragam. Saran penelitian selanjutnya dapat menguji coba pengaruh lebar louver dan jenis material louver terhadap daylighting level dan uniformity ratio sehingga dapat diketahui berapa lebar louver dan jenis material yang paling mampu mengoptimalkan daylighting.

PAWON: Jurnal Arsitektur, Nomor 02 Volume 5, Juli-Desember Tahun 2021, ISSN 2597-7636 


\section{DAFTAR PUSTAKA}

Ekasiwi,S.N., Antaryama, I.G.N., Sudarma, E., Defiana, I., Dinapradipta, A., Samodra, T.B., Soemardiono, B., Irvansyah., Sukma,A., dan Erwindini,C. (2020), "Peningkatan Kenyamanan Termal dan Pencahayaan Alam Gedung Sekolah Dasar di Kawasan Padat Hunian di Surabaya", Jurnal Ilmiah Arsitektur dan Lingkungan Buatan, Vol. 18, Nomor 1, Hal 63-73.

Freewan,A.A, Shao Li, dan Riffat Saffa. (2009), "Interactions between louvers and Ceiling Geometry for Maximum Daylighting Performance", Renewable Energy Journal, Vol 34, Noor 1, Hal 223232.

Groat, Linda dan David, Wang, (2002), "Architectural Research Methods", Edisi kedua, John Wiley \& Sons, Inc., United States of America.

Sabtalistia, Y.A. (2017), "Optimalisasi Pencahayaan Alami dengan Alat Pembayang Matahari (Shading Device) pada Jendela Ruangan Kelas", Jurnal Muara Sains, Teknologi, Kedokteran, dan IImu Kesehatan, Volume 1, Nomor 1, Hal 196-203.

Sabtalistia, Y.A dan Wulanningrum, S.D. (2021), "Aplikasi Skylight dan Jendela untuk Optimalisasi Pencahayaan Alami pada Rumah Tinggal”, Jurnal Arsitektur: Pawon, Volume 5, Nomor 1, Hal 63-77.

SNI 6197:2020, Konservasi Energi pada Sistem Pencahayaan. Badan Standardisasi Nasional. Jakarta. 
